\title{
A Review on Using ANOVA and RSM Modelling in The Glass Powder Replacement of The Concrete Ingredients
}

\author{
Sevar Neamat ${ }^{1, *}$, Masoud Hassan ${ }^{2}$ \\ ${ }^{1}$ Department of Mechanical Engineering, College of Engineering, University of Zakho, Kurdistan Region-Iraq, \\ sevar.dilkhaz@uoz.edu.krd \\ ${ }^{2}$ Department of Computer Science, Faculty of Science, University of Zakho, Kurdistan Region-Iraq, masoud.hassan@uoz.edu.krd \\ Correspondence: sevar.dilkhaz@uoz.edu.krd
}

\begin{abstract}
The flat glass powder usage instead of sand is convenient in structurally serviceable and environmentally compatible concrete. The deposits of glass powder in fibres cement compounds manufacture may add significant technical, economic and environmental necessities. The cement material and cement replacement by glass powder is chosen as parameters of the concrete. When the waste glass is fined to very fine dust, it demonstrates a cementitious characteristic due to silica content. Statistical methods and techniques are heavily used in glass powder replacement. In this paper, fifteen papers are reviewed and investigated to check the availability of using the statistical and modelling system in discussing the glass powder replacement with some other ingredients results between 2012-2021. We found that most of the papers depended on the ANOVA test to perform their work. Moreover, central composite face-centred (CFC) and Response Surface Methodology (RSM) took a part in the studies. From the numerous replicas, a quadratic prototypical was supplied with waste glass powder in the numbers of the studies that the glass waste powder is the best with its characteristics.
\end{abstract}

Keywords: RSM, ANOVA statistical analysis, glass powder, concrete.

Received: March 12 $2021 /$ Accepted: June $25^{\text {th }}, 2021 /$ Online: June $30^{\text {th }}, 2021$

\section{INTRODUCTION}

Concrete material is widely used today in various constructional applications, in the world, such as buildings, dams, bridges, sidewalks etc [1]. [2] The use of recycled waste materials in concrete structures is among the most attractive procedures because of the large number of consumptions of materials [3]

The glass powder is a very fine powder that is made of ground glass. In many industrial and craft applications, glass powder has advantages and is available in glass and industrial suppliers. At the time which is ground to a powder, glass converts to the best natural pozzolans which are improving the concrete's fresh and hardened characteristics. Though concrete is in its plastic stage, glass powder will upsurge its workability, so minimum energy, cost and time are obligate to place and combine the concrete.

Glass is a man-made material which is used since the ancient era. It is fabricated in different forms namely flat glass, container glass, bulb glass and others with a limited life of [4]. Thus, waste glass needs to be recycled and reused to protect the environment, where this material is considered as completely recyclable waste without any loss in quality [5],[6]. Rapid modernization and urbanization in many cities around the world have a great impact on increasing the rate of municipal solid waste materials, especially in developing countries. Recently, there have been modern growing ideas about the material.

Various types of statistician methods and software are been used in the glass powder effects analysis with the reinforced concrete beams such as ANOVA test, SPSS software, RSM modelling, $\mathrm{R}$ language and Python language. In this review, we focus our discussion on the ANOVA test because it was repeated more than 10 times in the papers we reviewed.

ANOVA is considered a noticeable type of hypothesis testing in the statical processes which is heavily used in the experimenting of Data. A test which is resulted from the calculating of the null hypothesis and the sample is statistically important if it is considered unlikely to have happened by chance, considering the fact of the null hypothesis (Neamat 2019a)[7]. Fundamentally, you're challenging collections to see if there's a modification between them. Illustrations of in which time you could need to test various groups. 
The one-way test means that you have only one independent factor with two levels. While the two-way ANOVA test illustrates that you have two independent variables with multiple levels. Two-way ANOVA with no replication: used at the time that you have one group with a double-testing of a similar group. For instance, you're challenging one set of individuals earlier and after they take medicine to see if it benefits or not.

\section{LITERATURE REVIEW}

Research provides by the author in [8] illustrated the experimental and statistical models to upsurge the performance of ultra-high performance concrete (UHPC) with dropping a cement consumption. Through testing the 28-day compressive strength, the mechanical characteristics were gotten. The rheologic feature was initiated by undertaking the flow test. CFC (central composite face-centred) and (RSM) were used in numbering and randomize orders of experiments. Numerous models such as a quadratic model were proposed together with a glass powder waste accumulation on compressive strength of UHPC [9]. It characterizes that there was an ideal waste glass powder. The addition of glass waste powder upsurged 28 days compressive strength, drying shrinkage, with a flowability of UHPC. A communication influence between nano-silica and waste glass powder has experimented on 28 days compressive strength with drying shrinkage. In a study performed by(Jurczak and Szmatuła 2021), the tasters remained then verified in regulating an effect of glass waste dust on the chief characteristics of organized concrete mixtures with the performance of the concrete once toughened. A paper offering the outcomes of investigation with an opportunity of replacement fly ash in accordant recycled waste glass in lowerstrength concrete mixes. The samples tested for 7 and 28-day compressive strength, water absorption, and freeze-thaw resistance in the water. The test consequences and their examination let us accomplish and mix the covering glass powder which is not only equal to cover the fly ash but even outpaces them by a wide boundary in accordance to durability.

The authors of [11] investigated the replacing of fine aggregate with the glass powder wastage in stages of $10 \%, 20 \%$, $30 \%$ and $40 \%$ correspondingly by the quantity of cement with the impacts on compressive strength, split tensile strength, workability and flexural strength. It originated that the compressive, flexural and split tensile strengths of concrete upsurge primarily with glass dust rise to reach a max range at about $20 \%$ and far ahead decrease[12]. Concrete workability is decreased monotonically by replacing proportion upsurges. A cement replacing up to about $20 \%$ with glass powder may be completed with no surrendering the compressive strength. In the study prepared by [13], there is a necessity in changing a portion of fine aggregate in accordance to a glass waste dust in decreasing the fine aggregate consuming with ecological contamination which may be patterned in an approximate degree.

Some studies have revealed that glass waste may be efficiently used as a fine aggregate in concrete. The glass waste once stranded to highly fine dust demonstrates some cementitious characteristics because of silica content. Consequently, the cut-glass dust in approximate degree may substitute the cement and fine aggregate donates to strong progress with improving the toughness of concrete. [14]

The statistical Examination software can integrate, analyses, interpret a huge amount of data in a statistical outline. It can put on numerous statistical tests and classify data for discovering sole readings. It can compare two or more variables to discover statistical comparisons or variations. Analysis of Variance (ANOVA, is a statistical method used to regulate if changes in mean values between three or additional collections are by chance or if they are certainly meaningfully dissimilar. ANOVA is very useful when examining the multi-item scales mutual in market research. The author functioned in the research of [15] illustrated that the glass is an unknown substantial containing a high percentage of silica content $(\mathrm{SiO} 2)$ i.e. $72 \%$ with waste glass once ashore to a highly fine powder (600 microns) responds to alkali in cement \& cementations production in assisting the donate to a strong expansion. [16], replacing the coconut shell with coarse aggregate once studying the transportation characteristics of concrete with coconut shells (CS) with replacing of coarse aggregate. He decided that an upsurge in coconut shells (CS) proportion reduced the concrete percentage with (CS) fraction remained augmented in the 7 days curative strong point and is also enlarged of conforming 28 days curing strength. In the [17] the powder of glass is supplied as a fine aggregate; delivering with the huge volume of hydration production. An additional addition of glass in concrete deviated from the concrete paste construction. A consequential adhesive covers extra of the durable calcium silicate hydrate $(\mathrm{CS}-\mathrm{H})$ than conservative commentate. In the research completed by [18] substituted the predictable rough aggregate and coconut shell and determined with $50 \%$ replacing coarse aggregates with coconut shells, the strength reached decreases habitually from $10 \%-20 \%$ as related to the predictable coarse aggregate concrete. By replacing $50 \%$ standby of coarse aggregates with coconut shells, the flexural strength achieved decreases invariably from $10 \%-15 \%$. Current inspection inspects the motorized conduct of concrete with secondhand sums from precast fragments and left-over glass. The research of [19] presented that cement adhesives of glass powder residue display a high hydration warmth in judgement to the control. The fifty per cent by weight replacing of cement to glass powder particles upsurges a flexural strength of composites at eight days and afterwards the durability tests. The recycling of usable glass powder saved valuable characteristics of the glass. Also, it provides the ability to recover and reuse it. It is considered a good way to reserve related ordinary resources and decrease environmental loads. The study covered an experiment made on the foundation of the central compound design. The accepted research program largely comprised the description of the concrete compressive strength, water absorption and freezethaw confrontation after 25 and 100 cycles of freezing and thawing. Up to the chosen system, the features of air voids in toughened concrete were also defined[10]

The outcomes displayed the production of 1-ton cement incompletely substituted by glass powder particles needs less energy than the cement somewhat substituted by limestone. In the end, conferring to research, usage of the glass powder deposit in the producing of fibres cement compounds may offer significant technical, environmental and economic assistance. 
The glass powder remainder using in the cement industry fibres can make significant profits in the consumption of cement and development of toughness of fibres in the cement matrix.

This research displays the analytical with optimization competencies of response surface methodology through admiration of new toughened characteristics of waste tire steel fibre reinforced concrete covering limestone dust. RSM has the benefit of instantaneously changing selected independent variables to offer a valuable prototypical of all reply differences. The variance analysis method (ANOVA) of all possessions stipulates that the adapted quadratic model stayed talented to positively forecast the fresh and hardened characteristics of fibre reinforced concrete with constant fortitude varying between 0.86 and 0.98 . Additionally, RSM model prognostic competence was prepared as actual good for compressive strength, excruciating tensile strength, slump and water absorption and satisfactory for FS with Nash \& Sutcliffe constant of model competence[4].

The replacing of cement and cement content by the glass dust were chosen as the limits in this study. In investigating the impact of cement content by replacing cement with glass powder, 117 cubes remained cast and verified under compression. The consequences were demanded that an increase of the compressive strength was done in adding extra cement contented to the mix and replacing of cement with glass powder up to $14 \%$ and $5 \%$, correspondingly. The compressive strength is originated to be upgraded up to $14 \%$ due to adding extra cement to the mix up to $70 \%$ from the control mix. The projected model has a good arrangement with the outcomes in this research.

Researchers have examined the glass possesses pozzolana characteristics according to an upsurge in silica content, so it may be substituted by fine aggregate to some degree with improving strength with increasing a concrete toughness. The chemical conformations of coconut shells occupied underneath research are nearly alike to that of normal cement. The percentage of minerals with combinations has functioned in testing cubes for their workability, compressive strength and flexural strength. The mixing of both recycled resources authorize are growing the quantity of recycling coarse which aggregates the plummeting damage of the concrete mechanical performance. As a result, enhancing an ecological rate of last substantial. All models have expounded under workshop circumstances and unmolded after $24 \pm 2$ hours. Future, they were flooded in water with lime at $23 \pm 3{ }^{\circ} \mathrm{C}$ throughout the suitable curing time[20].In this specific study, the joint performance of fine used concrete aggregates with glass powder of various element sizes in types of cement was considered. Various combinations are investigated to diminish losses in mechanical possessions with the toughness to capitalize on the quantity of replacing resources. According to the late pozzolanic response of the glass powder, the samples display the extremely acceptable consequences at 90 days of curing, by standards of their characteristics adjacent to those of the control mortar [21]

In the investigation donated by the impact of the glass waste dust with possible cementitious substantial of slag mortar stimulated by the combination of water glass and sodium hydroxide. Likewise, the Fundamental compound project and answer surface technique were used for the optimization of the alkali content (sodium oxide equivalent) and an additional ratio of waste glass dust in maximizing the flexural and compressive strengths. [22].

\section{METHODS}

This review is prepared following the guidelines of the systematic literature analysis to achieve the research objects. According to international Databases such as ScienceDirect, Scopus, Springer, and IEEE, the keywords such as "ANOVA", "RSM" or "Glass powder " were searched for the published papers between 2012 to 2021. Firstly, around 35 papers were found. After the screening, some irrelevant papers were excluded. The rest of the studies were precisely screened, and 15 papers have finally been selected that address the objectives of this review. The present proposed study aims to discover how the ANOVA method can be used in civil engineering analyzing subjects. Also, to compare the methods and equations of the ANOVA method with RSM methods. Results modelling and analysis were completed through utilizing the reply surface procedure (RSM) whichever a mixing of statistic mathematic methods valuable in showing with analyzing of the dissimilar subjects. The competence of methods was projected by the usage of (ANOVA) which is presenting the value of designated parameters.

The ANOVA test table can be seen in the table1 (The ANOVA table for the two factors model), Table 2: Some equations used in the ANOVA Software. The Response Surface Methodology(RSM) in the statistic discovers the associations between several descriptive factors and one or more than one response feature. The technique was familiarized by George E. P. Box and K. B. Wilson in 1951. The chief impression of RSM is using a sequence of planned tests to gain the best answer. Statistical methods such as RSM can be worked to capitalize on the production of a special substance by optimization of operational factors. Of late, for preparation optimization, the RSM, using an appropriate design of experiments, has become widely used [23]. In contrast to predictable methods, the communication among procedure variables can be resolute by statistical techniques[24].

The Portland cement concrete compressive strength has been analyzed in the specified research in reply to the assimilation of $5 \%, 10 \%$ and $20 \%$ of smooth glass powder by the amount of sand. The study suggests that the smooth glass powder using in the residence of sand in the aforementioned proportions of practicable in the appropriate concrete production as a structure and environmental use [25]. Two-way ANOVA with replication: Two groups and the members of those groups are doing more than one thing. For example, two groups of patients from different hospitals trying two different therapies. 
TABLE I. THE ANOVA TABLE FOR THE TWO FACTORS MODEL

The Anova table for the two factor model (A - fixed, B - random)

$$
y_{i j k}=\mu+\alpha_{i}+\beta_{j}+(\alpha \beta)_{i j}+\varepsilon_{i j k}
$$

\begin{tabular}{|c|c|c|c|c|c|}
\hline Source & SS & $d f$ & MS & EMS & F \\
\hline $\mathrm{A}$ & $\mathrm{SS}_{\mathrm{A}}$ & $a-1$ & $\mathrm{MS}_{\mathrm{A}}$ & $\sigma^{2}+n \sigma_{A B}^{2}+\frac{n b}{(a-1)} \sum_{i=1}^{a} \alpha_{i}^{2}$ & $\mathrm{MS}_{\mathrm{A}} / \mathrm{MS}_{\mathrm{AB}}$ \\
\hline $\mathrm{B}$ & $\mathrm{SS}_{\mathrm{A}}$ & $b-1$ & $\mathrm{MS}_{\mathrm{B}}$ & $\sigma^{2}+n a \sigma_{B}^{2}$ & $\mathrm{MS}_{\mathrm{B}} / \mathrm{MS}_{\mathrm{Error}}$ \\
\hline $\mathrm{AB}$ & $\mathrm{SS}_{\mathrm{AB}}$ & $(a-1)(b-1)$ & $\mathrm{MS}_{\mathrm{AB}}$ & $\sigma^{2}+n \sigma_{A B}^{2}$ & $\mathrm{MS}_{\mathrm{AB}} / \mathrm{MS}_{\mathrm{Errror}}$ \\
\hline Error & $\mathrm{SS}_{\mathrm{Error}}$ & $a b(n-1)$ & $\mathrm{MS}_{\mathrm{Error}}$ & $\sigma^{2}$ & \\
\hline
\end{tabular}

Note: The divisor for testing the main effects of $A$ is no longer $M S_{\text {Error }}$ but $M S_{A B}$.

TABLE II. The Some EQUATIONS USED IN The ANOva Method.

\begin{tabular}{|l|l|l|}
\hline$S S_{T}=\sum_{k} \sum_{j} \sum_{i}\left(x_{i j k}-\bar{x}\right)^{2}$ & $d f_{T}=n-1$ & $M S_{T}=S S_{T} / d f_{T}$ \\
\hline$S S_{A}=m c \sum_{i}\left(\bar{x}_{i}-\bar{x}\right)^{2}$ & $d f_{A}=r-1$ & $M S_{A}=S S_{A} / d f_{A}$ \\
\hline$S S_{B}=m r \sum_{j}\left(\bar{x}_{j}-\bar{x}\right)^{2}$ & $d f_{B}=c-1$ & $M S_{B}=S S_{B} / d f_{B}$ \\
\hline$S S_{A B}=m \sum_{j} \sum_{i}\left(\bar{x}_{i j}-\bar{x}_{i}-\bar{x}_{j}+\bar{x}\right)^{2}$ & $d f_{A B}=(r-1)(c-1)$ & $M S_{A B}=S S_{A B} / d f_{A B}$ \\
\hline$S S_{W}=\sum_{k} \sum_{j} \sum_{i}\left(x_{i j k}-\bar{x}_{i j}\right)^{2}$ & $d f_{W}=n-r C$ & $M S_{W}=S S_{W} / d f_{W}$ \\
\hline
\end{tabular}

\section{METHODS}

Analyzing of the variance (ANOVA) utilized in the validation of models used in the study accomplished in [8]. The study resulted in the upgrading of the characteristics of UHPC. The activities with communications and features of UHPC performances were showed by ANOVA. To find the finest replicas, linear, quadratic, and two-factor communication prototypical were measured in discovering the greatest precise replicas. Superiority in the usable models was itemized by the constant of the several resolve R2, which shows the whole eccentricity of the features for every method.

A likelihood of errors (P-value) with a $95 \%$ confidence level with a statistical significance test at $5 \%$ was achieved for model authentications. the ANOVA consequences for three dissimilar answers. The outputs illustrate that the replicas were important at the $5 \%$ level of confidence due to the quantity of P-values which was less than 0.05 .

These forecasts were authenticated with a respectable correlation between a judgement of the experimental with the projected standard by the absolute relative percentage mistake of $0.842, \quad 11.35,3.6,18.22$ and 2.04 for water consumption/absorption, compressive strength flexural strength, split tensile strength and slump separately. Planned mathematic replicas are accomplished by forecasting the essential fresh and hardened characteristics of fibre-reinforced concrete to notify initial conclusion creation when used in construction[26]. A paper displays the investigational outcomes of research approved involving the compressive strength with slump flow of ultra-high-performance concrete (UHPC) made the cementitious blends of recycled glass flour, recycled glass powder, micro limestone powder, silica fume, and portland cement. The adopted second-order polynomic regression model provided an accurate correlation between the considered variables and the obtained responses. Numerical optimization was then performed to get an eco-friendly combination with the appropriate flow, highest compressive strength, and minimum content of cement. The use of $603 \mathrm{~kg} / \mathrm{m} 3$ of cement in the mixture can be considered as the most appropriate amount to be employed in UHPC mixtures, fulfilling the limit values of compressive strength and spread flow. [27]

In the study conducted by the authors in [19], the statistical analysis was accomplished using Statistical software (version 13.4.0.14). Afterwards an examination of the ANOVA statement, a valuation was distracted by totally randomized design (CRD) and a judgement among the average standards by Tukey test at $5 \%$ significance level.

(ANOVA) was accomplished after 7, 14 and 28 times of curing. The compressive strength test outcomes designate that the concrete covering a w/c ratio of 0.50 can be utilized for structural requests, nevertheless, the glass waste contented, which can be used with a w/c ratio of 0.55 covering $20 \%$ of glass waste [29].

This investigation proposes the united properties of gapgraded cement mixed by extra cementitious supplies (SCMs) in the usage of (RSM). A three-level factor Box-Behnken design (BBD) is prepared in deliberating subsequent self-governing factors: fly ash (FA), quartz powder (QP) and silica fume (SF). Linear, quadratic, and communication association among main characteristics (original variability, rheologic features, hydration warmth, motorized features, and volume constancy) and compound cementitious resources of gap-graded cement paste which are deliberated.

Analysis of variance (ANOVA) consequences designate that SF has an important impact on all main possessions of the mixed cement pastes. The composite desirability function value is 0.939. Henceforth, multi-objective optimization is an actual technique for enhancing the fresh and hardened characteristics of multifaceted cement pastes containing SCMs[27]

An investigational and statistical examination is approved out to examine the effects of three inputs (limestone powder, glass powder, and alkali content) on the presentation of alkali stimulated slag mortar. Response surface methodology (RSM) was utilized to prepare all prepared responses like 28-day flexural and compressive strength, water absorption, and dry shrinkage. Examination and alteration presented that all industrialized models were statistically important. Optimization was accomplished using the attractiveness method of the RSM to make the most of 28-day flexural and compressive strength while minimizing water absorption and drying shrinkage. (Zhang and Zhai 2020).

The SPSS software package was utilized in the planned equation to forecast compressive strength comprised of a mixed amount of UHPC using nonlinear numerous reversions[30]. A planned archetypal was presented in that it has a good arrangement with test outcomes. [33] 
Consequences will be analyzed by applying ANOVA. Depending on the degrees of freedom (df), the sum of squares $(\mathrm{S})$ and the variance $(\mathrm{V})$ of every one of the constraints, their importance is resulted to assess their absolute contribution at the end. This method will measure the impact of each adjustable in the final characteristics of the substance can be evaluated to offer the best mixture of the levels of the four variables.

In the research prepared by the authors [21], the consequences are hopeful once glass powder with slighter size of particles is utilized according to its filler impact joint with its pozzolanic action, the creation which is conceivable to substitute up to $20 \%$ of glass powder to a supreme size of $38 \mathrm{~mm}$. To regulate which mutable has a statistically important impact on the mechanical and toughness possessions of the examples, ANOVA for every possession at 28 and 90 days of the situation was achieved, correspondingly. The implication used is 5\%, i.e., a $95 \%$ likelihood that the impact is important. To approximate the fraction part of every feature in the value of each possession, the sum of squared differences (SSD) of every feature is used with admiration to the total of SSD differences. From this is got the $\mathrm{R} 2$ related with the one produced by each ANOVA analysis, it presents the ratio between the sum of all the differences of the issues of the model and total model variation. The analysis variance results (ANOVA) designated that the accurateness of the industrialized strength replicas depended on the answer surface technique was acceptable [22].

\section{CONCLUSIONS}

The study on the long-term performance of concrete made with glass powder waste is still limited. Additionally, the design of the effective material constitutive relations for waste glass powder concrete is not available extensively to forecast the presence of members at various load ages in finite element simulation. Additional studies in these orders are measured vital relied on the products and the model projected. In this review study in forecasting the compressive strength and the flexural strength effectiveness by replacing the cement in concrete with glass powder, the ANOVA statistical analysis is considered the most usable method with the RSM (Response Surface Modeling) in most of the reviewed papers. Also, the test outcomes were demanded that the compressive strength was improved by adding extra cement content to the mix and replacing cement with glass powder.

\section{REFERENCES}

[1] S. Ghannam, H. Najm, and R. Vasconez, "Experimental study of concrete made with granite and iron powders as partial replacement of sand," Sustainable Materials and Technologies, vol. 9, pp. 1-9, 2016.

[2] S. Neamat, "Models Developed for Creep of High Strength Concrete," International Journal of Civil,Mechanical and Energy Science, vol. 3, no. 3, pp. 174-180, May 2017.

[3] H. Karimi, S. Neamat, and S. Galali, "Application of Mathematical Matrices for Environmental Impact Assessment, A Case Study of Thermal Power Plant," Journal of Applied Science and Technology Trends, vol. 1, no. 1, pp. 13-16, 2020.

[4] T. Awolusi, O. Oke, O. Akinkurolere, and A. Sojobi, "Application of response surface methodology: Predicting and optimizing the properties of concrete containing steel fibre extracted from waste tires with limestone powder as filler," Case studies in Construction materials, vol. 10, p. e00212, 2019.
[5] K. Sobolev, P. Türker, S. Soboleva, and G. Iscioglu, "Utilization of waste glass in ECO-cement: Strength properties and microstructural observations," Waste Management, vol. 27, no. 7, pp. 971-976, 2007.

[6] Z. Z. Ismail and E. A. Al-Hashmi, "Recycling of waste glass as a partial replacement for fine aggregate in concrete," Waste management, vol. 29, no. 2, pp. 655-659, 2009.

[7] S. Neamat and I. Yitmen, "Factors Affecting the Innovation and Competitiveness in Kurdistan Region of Iraq Construction Industry," Int. J. Adv. Eng. Res. Sci. IJAERS, vol. 4, no. 2, pp. 157-162, 2017.

[8] M. A. Mosaberpanah, O. Eren, and A. R. Tarassoly, "The effect of nanosilica and waste glass powder on mechanical, rheological, and shrinkage properties of UHPC using response surface methodology," Journal of Materials Research and Technology, vol. 8, no. 1, pp. 804-811, 2019.

[9] Y. Z. DINKHA, J. H. HAIDO, and M. H. ALI, "FLEXURAL BEHAVIOR OF REINFORCED CONCRETE BEAMS MADE WITH ORDINARY AND HIGH STRENGTH CONCRETES: EFFECT OF INTERFACIAL ROUGHNESS BETWEEN OLD AND NEW CONCRETES,” Journal of Duhok University, pp. 570-579, 2017.

[10] R. Jurczak and F. Szmatuła, "Evaluation of the Possibility of Replacing Fly Ash with Glass Powder in Lower-Strength Concrete Mixes," Applied Sciences, vol. 11, no. 1, p. 396, 2021.

[11] R. Sakale, S. Jain, and S. Singh, "Experimental investigation on strength of glass powder replacement by cement in concrete with different dosages," International Journal of Advanced Research in Computer Science and Software Engineering, vol. 5, no. 12, pp. 386-390, 2015.

[12] S. Neamat, "Investigation of FRP impact on Shear Strengthening of Reinforced and Pre-Stressed Concrete Beams," research review, vol. 9, p. 11, 2020.

[13] S. Chikhalikar and S. Tande, "An experimental investigation on characteristics properties of fibre reinforced concrete containing waste glass powder as pozzolona," presented at the 37th Conference on Our World in Concrete and Structures, Singapore, August, 2012.

[14] M. H. Ali, Y. Z. Dinkha, and J. H. Haido, "Mechanical properties and spalling at elevated temperature of high performance concrete made with reactive and waste inert powders," Engineering Science and Technology, an International Journal, vol. 20, no. 2, pp. 536-541, 2017.

[15] V. V. Bhat and N. B. Rao, "Influence of glass powder on the properties of concrete," International Journal of Engineering Trends and Technology, vol. 16, pp. 196-199, 2014

[16] A. Yerramala and C. Ramachandrudu, "Properties of concrete with coconut shells as aggregate replacement," International journal of engineering inventions, vol. 1, no. 6, pp. 21-31, 2012.

[17] R. Vandhiyan, K. Ramkumar, and R. Ramya, "Experimental study on replacement of cement by glass powder," Int. J. Eng. Res. Technol, vol. 2 , no. 5, pp. 234-238, 2013.

[18] D. Shraddha, F. Hitali, D. Pradeep, and S. Varpe, "Sustainable concrete by partially replacing coarse aggregate using coconut shell," 2014 .

[19] L. Rodier, V. da Costa Correia, and H. S. Junior, "Elaboration of ecoefficient vegetable fibers reinforced cement-based composites using glass powder residue," Cement and Concrete Composites, vol. 110, p. 103599, 2020.

[20] V. Letelier, E. Tarela, R. Osses, J. P. Cárdenas, and G. Moriconi, "Mechanical properties of concrete with recycled aggregates and waste glass," Structural Concrete, vol. 18, no. 1, pp. 40-53, 2017.

[21] V. Letelier, B. I. Henríquez-Jara, M. Manosalva, and G. Moriconi, "Combined use of waste concrete and glass as a replacement for mortar raw materials," Waste Management, vol. 94, pp. 107-119, 2019.

[22] L. Zhang and Y. Yue, "Influence of waste glass powder usage on the properties of alkali-activated slag mortars based on response surface methodology," Construction and Building Materials, vol. 181, pp. 527$534,2018$.

[23] J. R. Karmoker, I. Hasan, N. Ahmed, M. Saifuddin, and M. S. Reza, "Development and Optimization of Acyclovir Loaded Mucoadhesive Microspheres by Box-Behnken Design," Dhaka University Journal of Pharmaceutical Sciences, vol. 18, no. 1, pp. 1-12, 2019.

[24] N. Asadi and H. Zilouei, "Optimization of organosolv pretreatment of rice straw for enhanced biohydrogen production using Enterobacter aerogenes," Bioresource technology, vol. 227, pp. 335-344, 2017. 
[25] E. J. P. de Miranda Júnior, H. de J. C. L. Bezerra, F. S. Politi, and A. E. M. Paiva, "Increasing the compressive strength of Portland cement concrete using flat glass powder," Materials Research, vol. 17, pp. 45-50, 2014.

[26] S. Neamat and M. Shamsborhan, "The Investigation of The Different Types of the Ground Rebar Spacers with Proposing New Design Rebar Space Mixed of Concrete Plastic," Journal of Civil Engineering Frontiers, vol. 1, no. 1, pp. 01-06, 2020.

[27] J. Abellán, J. Fernández, N. Torres, and A. Núñez, "Statistical optimization of ultra-high-performance glass concrete," ACI Materials Journal, vol. 117, no. 1, pp. 243-254, 2020.

[28] S. Neamat and H. Karimi, "A systematic review of GIS-based landslide Hazard Mapping on Determinant Factors from International Databases," in 2020 International Conference on Advanced Science and Engineering (ICOASE), Dec. 2020, pp. 180-183. doi: 10.1109/ICOASE51841.2020.9436611.

[29] E. J. P. de Miranda Júnior, H. de J. C. L. Bezerra, F. S. Politi, and A. E. M. Paiva, "Increasing the compressive strength of Portland cement concrete using flat glass powder," Materials Research, vol. 17, pp. 45-50, 2014.

[30] S. Neamat, "Factors Affecting Project Performance in Kurdistan Region of Iraq," International Journal of Advanced Engineering Research and Science, vol. 4, no. 5, pp. 01-05, 2017.

[31] S. Neamat, "Risk Assessment for Uzun Construction and Real Estate Company in TRNC".

[32] L. Zhang and J. Zhai, “Application of response surface methodology to optimize alkali - activated slag mortar with limestone powder and glass powder," Structural Concrete, 2020.

[33] F. Karim, B. Abu Bakar, C. Kok Keong, and O. Aziz, "Influence of cement and glass powder on the compressive strength of ultra-high performance concrete," International Journal of Engineering Trends and Technology, vol. 35, pp. 243-246, 2016.

[34] S. Neamat, "Human Resource Management with Strategic Development," Journal of Civil Engineering Frontiers, vol. 1, no. 1, pp. 16-19, 2020. 